Aizenkot, D., \& Kashy-Rosenbaum, G. (2020). The effectiveness of safe surfing, an anti-cyberbullying intervention program in reducing online and offline bullying and improving perceived popularity and selfesteem. Cyberpsychology: Journal of Psychosocial Research on Cyberspace, 14(3), Article 6.

\title{
The Effectiveness of Safe Surfing, an Anti-Cyberbullying Intervention Program in Reducing Online and Offline Bullying and Improving Perceived Popularity and Self-Esteem
}

\author{
Dana Aizenkot \& Gabriela Kashy-Rosenbaum \\ Ashkelon Academic College, Ashkelon, Israel
}

\begin{abstract}
Schools have been fighting cyberbullying through intervention programs, yet few interventions have been empirically evaluated. This study evaluates the effectiveness of a Safe Surfing anti-cyberbullying intervention program that is based on the theory of planned behavior in reducing bullying online and offline and improving student-perceived popularity and self-esteem. It was hypothesized that from pre- to post-intervention online and offline bullying rates will decrease; students' negative perception of popularity will decrease; students' self-esteem will increase, and; in classrooms where there has been a greater decrease in online and offline bullying following the intervention there will be a greater improvement in students' negative perception of popularity and self-esteem. Data were collected from 1,550 students (53\% males) in $3^{\text {rd }}$ to $11^{\text {th }}$ grades from 69 classes in 19 primary (68\%), middle and high (32\%) public schools in Israel. The students answered online questionnaires pre-and postintervention. Results indicated a significant decrease in bullying online and offline post-intervention. Also, a significant improvement in perceived popularity and self-esteem was obtained among primary school students. The decrease in bullying online and offline was significantly associated with an improvement in perceived popularity and self-esteem. The study provides support for the positive role that school-based interventions against cyberbullying can have, and demonstrates that schools can make a difference in the way their students consume social networks. The findings also contribute to the debate about the co-occurrence between traditional bullying and cyberbullying. The findings may encourage school principals to approach peer victimization with a broader view and to develop intervention programs that capture students' social experiences more holistically.
\end{abstract}

Keywords: Cyberbullying; social networks; traditional bullying; intervention programs; self-esteem; perceived popularity; students

\section{Introduction}

The development of information and communication technologies has brought many benefits for youth (O'Keeffe et al., 2011), but also threats and risks (Aizenkot \& Kashy-Rosenbaum, 2019). One such risk has been conceptualized as cyberbullying (Tokunaga, 2010). Students involved in cyberbullying often know each other from school (Hinduja \& Patchin, 2008), and those of them who are bullied online are frequently bullied offline as well (Twyman et al., 2010). In fact, studies have found continuity and co-occurrence between traditional bullying and cyberbullying among classmates (e.g., Aizenkot, 2017a). Cyberbullying is therefore perceived as a school-based problem, and achieving its sustainable reduction requires interventions that are implemented within the school (Wölfer et al., 2014). However, while there has been an increase in research on cyberbullying-related issues, 
evaluation research on the effectiveness of school-based intervention programs in reducing cyberbullying is needed (Ortega-Barón et al., 2019).

Cyberbullying victimization is negatively related to student well-being (Machimbarrena et al., 2018) and selfesteem (Extremera et al., 2018), and traditional bullying victimization is negatively associated with studentperceived popularity (Cook et al., 2010). To date, findings concerning the relation between cyberbullying victimization and perceived popularity have been inconsistent (Badaly et al., 2013; Gradinger et al., 2012; Ranney \& Troop-Gordon, 2020; Wright, 2014, 2015).

Given the need for evaluation research of anti-cyberbullying intervention programs (Gaffney et al., 2019), as well as the harmful consequences for the victims (Erdur-Baker \& Tanrıkulu, 2009), the present study aims to evaluate the effectiveness of Safe Surfing, a widely implemented anti-cyberbullying intervention program for primary, middle and high school students, in reducing bullying online and offline and improving student-perceived popularity and self-esteem. The intervention program is based on the theory of planned behavior (TPB) (Ajzen, 1991), a theoretical framework that has been espoused to explain and intervene in cyberbullying research (Wölfer et al., 2014).

The findings of this study may have implications for the development of intervention programs in the school setting and may contribute to the debate about the co-occurrence between traditional bullying and cyberbullying.

\section{Traditional Bullying and Cyberbullying Victimization}

School bullying, conceptualized as repeated violence intentionally perpetrated by some students on other peers, physically or psychologically weaker (Olweus, 1991), is present in schools all over the world (Craig et al., 2009) and can take on many forms, including physical (punching or kicking, seizing or damaging other people's belongings), verbal (ridiculing, insulting, repeatedly mocking someone, making racist remarks), relational (leaving one or more peers out of aggregation groups) and indirect (spreading rumors or gossip about a student) (Olweus, 1993).

In recent years, as a result of information and communication technologies development and the widespread use of smartphones and internet access, bullying has penetrated the cyberspace, conceptualized as cyberbullying, an intentional aggressive behavior repeated over time through the use of electronic devices against victims who cannot easily defend themselves (Tokunaga, 2010). Cyberbullying can be reflected in many forms, such as verbal bullying (mockery, curses, insults, derogatory names, threats), doxxing (posting personal photos without consent, publishing unsolicited content and posting personal and sensitive information about a student) and exclusion (exclusion from a classmates' group and group rejection) (Aizenkot, 2017a). Cyberbullying behaviors seem to be learned through social relationships with family members and peers (Tanrikulu, 2019). In review research that examined the potential resources that perpetrators use to learn how to cyberbully others, Tanrikulu (2019) found that social relations with siblings and peers, as well as adults at home and at school, were the main resources that school children use to learned cyberbullying perpetration. It was explained that a young person's social life is generally formed by relationships at home and at school. Siblings, peers or adults, in either setting, who engage in cyberbullying, can lead a young person to become aware of cyberbullying and act as a cyberbullying perpetrator.

Traditional bullying and cyberbullying have some features in common, such as the possible imbalance of power between the aggressor and the victim, and the intentionality and repetition of the aggressive behavior (Navarro et al., 2015). These similarities led some researchers to consider cyberbullying as a modality of traditional bullying (Erdur-Baker, 2010; Li, 2007; Slonje et al., 2017; Wang et al., 2009; Ybarra et al., 2012). In fact, several studies have found continuity between traditional bullying and cyberbullying (Aizenkot, 2017a; Kowalski et al., 2012; Lazuras et al., 2017; Olweus, 2013), supported by the connection between the offline and online environments (MartínezFerrer et al., 2018). It has therefore been argued that there is co-occurrence and functional similarity between cyberbullying and traditional bullying, and that cyberbullying may be merely another form of bullying, supported by technological tools and reflected in the cyberspace (Mitchell \& Jones, 2015). Waasdorp and Bradshaw (2015) supported this argumentation by finding that over $50 \%$ of the cybervictims had been victimized by traditional bullying as well. Similarly, Hinduja and Patchin (2010) showed that over $60 \%$ of adolescents were involved in both online and offline forms of bullying. Therefore, it is common for aggressive behavior emerging in the classroom to continue outside of the schoolyard, through the smartphone and the internet (Aizenkot, 2017a). 
Other researchers, however, argue that online and offline bullying are not overlapping (Law et al., 2012), and that cyberbullying has some specific characteristics which differentiate it qualitatively from traditional bullying, such as publicity, anonymity, and lack of supervision (Patchin \& Hinduja, 2006). The notion of a power imbalance is also different in the online and offline environments, as someone who is not socially influential can be technologically dominant (Law et al., 2012). The opportunities for aggression are also distinct in online and offline social contexts (Runions, 2013). The unique properties of the online environment, therefore, stress the importance of distinguishing between traditional bullying and cyberbullying (Wong \& McBride, 2018). The current study may contribute to the debate about the co-occurrence between traditional bullying and cyberbullying by examining the ability of an anti-cyberbullying intervention program to reduce traditional bullying.

The bullying in online and offline settings seems to produce a high level of psychological distress and behavior problems for the victims (Machimbarrena et al., 2018). Victims of traditional bullying and cyberbullying have low self-esteem (Extremera et al., 2018), feel socially rejected or isolated (Brown et al., 2005), and experience greater social marginalization and lower social status (Olweus, 1994). They also have a significantly amplified risk of school avoidance (Payne \& Hutzell, 2017), anxiety, depressive symptoms (Erdur-Baker \& Tanrıkulu, 2009), and suicidal ideation, more than children who are not bullied (Pham \& Adesman, 2015). The increased awareness of mental health problems that may stem from traditional bullying and cyberbullying victimization justify the importance of designing and implementing school-based anti-bullying programs (Ortega-Barón et al., 2019).

\section{Popularity and Self-Esteem in Adolescence}

Peer relationships are critical for social and emotional development in adolescence, and have been associated with school performance, delinquency, and psychological adjustment (Lonardo et al., 2009). Sullivan (1953) theorized that group-level acceptance is important for development. Consistent with this notion, research shows that popularity, as an important aspect of peer social status, is generally conceptualized as a shared recognition among peers that a particular child has achieved prestige, visibility, or high social standing (Adler et al., 1992). Sociometric and perceived popularity are distinct constructs, as sociometric popularity is a measure of how wellliked (vs. disliked) a child is by peers, whereas perceived popularity reflects a child's popularity (vs. unpopularity) and dominance within the social hierarchy (Parkhurst \& Hopmeyer, 1998). Perceived popularity is considered more predictive of adjustment in adolescence than sociometric popularity (Litwack et al., 2012), as growing empirical and qualitative evidence indicates that perceived popularity is highly valued in adolescence (de Bruyn \& van den Boom, 2005), and prized above achievement, friendship and romantic relationships (LaFontana \& Cillessen, 2010).

The attainment of high popularity may contribute to a notable sense of accomplishment and satisfaction, bolstering self-esteem (Litwack et al., 2012). Self-esteem, or individuals' subjective evaluation of their worth as persons (Marsh \& O'Mara, 2008), is an important aspect of development during adolescence. High self-esteem is a particularly salient aspect of positive development during adolescence (Trzesniewski et al., 2006), while low selfesteem places adolescents at risk for later maladjustment (Stice et al., 2004). Given that self-esteem is highly responsive to social evaluation and external feedback (Hank \& Baltes-Götz, 2019), research has shown that selfesteem is related to perceived popularity (de Bruyn \& van den Boom, 2005). For example, Litwack and colleagues (2012) found that perceived popularity made a unique contribution to adolescent adaptation, predicting less depressive affect and higher self-esteem. The great importance attributed to popularity during adolescence (LaFontana \& Cillessen, 2010) explains why perceived popularity makes a unique contribution to adolescents' wellbeing and self-esteem (Litwack et al., 2012). This may be explained given that high social status affords adolescents peer reinforcement in which they are sought out as friends, provided support, admired, and emulated (Sandstrom \& Cillessen, 2006).

Research on the relation between cyberbullying victimization and self-esteem found reciprocal negative associations between these factors (e.g., Extremera et al., 2018). Patchin and Hinduja (2010), for example, explored the association between adolescents' experience with cyberbullying and their self-esteem. Findings indicated that victims of cyberbullying, when compared to none-victims, showed lower levels of self-esteem. Similar results were found by Kowalski and Limber (2013). In the opposite direction, research found that students who experience lower levels of self-esteem are at an increased risk of cybervictimization (Palermiti et al., 2017). This is explained by the harmful implications of low self-esteem as a risk factor for young people (Hinduja \& Patchin, 2010). Self- 
esteem has been found to be lower in adolescent victims of both traditional bullying and cyberbullying (Perren et al., 2010). Research by Brighi and colleagues (2012) found that severe cyberbullying victimization was strongly linked to lower levels of adolescent self-esteem more than only occasional cyberbullying victimization, with victims who experienced both traditional bullying and cyberbullying reported the lowest levels. Based on these findings, it is hypothesized that, following intervention program implementation, students' self-esteem will increase. This increase is expected due to the increase in self-esteem among cyberbullying victims that will improve the total rate of student self-esteem.

A negative association was also found between traditional bullying victimization and perceived popularity (Cook et al., 2010). de Bruyn and colleagues (2010), for example, found that low perceived popularity strongly increased the likelihood of being victimized by peers. It was explained that bullying a peer who doesn 't have any friends carries a low risk of retaliation, and therefore unpopular children are easier targets.

Popularity in adolescence predicts heightened prosocial behavior, but also aggression and peer victimization in face-to-face contexts (de Bruyn \& van den Boom, 2005). Therefore, perceived popularity is related to enhanced adolescents' ability to control and influence the resources and behaviors of their peer group (Mayeux et al., 2011). Popular youth often display behaviors that enhance their social relationships and garner positive peer regard. However, popular youth can also utilize antagonistic and aggressive behaviors, with little censure from the peer group (Pellegrini et al., 2011). Consequently, popular adolescents are also at increased risk of peer victimization (Closson \& Wantanabe, 2018). Adolescents who are socially skilled in face-to-face environments demonstrate an enhanced ability to exploit digital technologies to fulfill personal goals (Desjarlais \& Willoughby, 2010). Accordingly, perceived popularity has been found to be positively associated with various cyber behaviors such as cyberaggression and cyber-prosocial behaviors among middle school students (Wright, 2014, 2015), and has been found to be positively correlated with cyber-aggression among secondary school students (Badaly et al., 2013). There is also evidence that popularity is associated with higher levels of cybervictimization. Gradinger and colleagues (2012) documented a positive concurrent association between popularity and cybervictimization for girls. In contrast, Badaly and colleagues (2013) found that popularity was positively associated with cybervictimization for boys, but not girls. Recent research that examined longitudinal associations between popularity and subsequent cyber-prosocial behavior, cyber-aggression, and cybervictimization, indicated that popularity predicts higher levels of cyber-prosocial behavior and cyber-aggression. However, findings also indicated that unpopular youth are at increased risk of cybervictimization (Ranney \& Troop-Gordon, 2020). Given the inconsistent findings regarding the relation between perceived popularity and cyberbullying victimization, and the findings regarding the negative relation between perceived popularity and traditional bullying victimization, and considering that a substantial number of cyberbullying victims are bullied by peers they know from school (Juvonen \& Gross, 2008), and that cyberbullying victims are often the same individuals who are victims of traditional bullying (Twyman et al., 2010), it is hypothesized that following the intervention program implementation students' perceived popularity will improve. This improvement is expected due to the improvement in perceived popularity among cyberbullying victims that will improve the total rate of student perceived popularity.

\section{Intervention Programs Against Cyberbullying}

Whereas a prevention study of cyberbullying aims to prevent cyberbullying experiences before they occur, an intervention study of cyberbullying aims to intervene in existing cyberbullying incidences and evaluate the intervention program that was implemented (Tanrikulu, 2018). Given the worldwide prevalence and the negative outcomes of cyberbullying, evaluation research of cyberbullying intervention programs that might increase the generalizability of such programs is needed (Tanrikulu, 2018); however, evaluation research on the effectiveness of intervention programs is needed (Ortega-Barón et al., 2019). Aiming to answer this challenge, Tanrikulu (2018) conducted a systemic review that analyzed seventeen published studies of prevention and intervention programs against cyberbullying in a school context. The review concluded that anti-cyberbullying programs are effective in reducing cyberbullying among school-aged youth, with the intention to prevent or reduce cyberbullying being the most significant element of these programs. Schools were found to be the main settings where prevention and intervention efforts can be practically and effectively performed with school-age children. Another comprehensive systematic review and meta-analysis that analyzed twenty-four published intervention programs against cyberbullying found that school-based intervention programs against cyberbullying are effective in reducing both cyberbullying perpetration and victimization (Gaffney et al., 2019). 
One theory that has been espoused to explain and intervene in cyberbullying research is TPB (Ajzen, 1991). TPB posits that people's intention to perform a certain behavior is the best predictor of their actual behavior. The behavioral intention, in turn, is determined by three belief-based concepts: (1) an attitude, i.e., a person's global affective evaluation of a behavior; (2) the subjective norm, the perception of what others think of the behavior; and, (3) the perceived behavioral control that is defined as the perceived ease or difficulty of performing the behavior. The more favorable the attitude and the subjective norm with respect to a behavior, and the greater the perceived behavioral control, the stronger should be an individual's intention to perform the behavior considered. Heirman and Walrave (2012) have demonstrated that TPB provides a useful model for studying cyberbullying. In their study, the three main factors explained $44.8 \%$ of the total variance of adolescents' intention to cyberbully.

Upon this theoretical perspective Wölfer and colleagues (2014) proposed a model of core principles for a cyberbullying reduction intervention program that included: (1) social skill competencies and social knowledge; (2) attitudes toward and awareness of possible cyberbullying consequences; (3) social responsibility and improving classroom climate; and, (4) strategies for coping with cyberbullying and for positive online communication. Aizenkot and Kashy-Rosenbaum (2018) followed these intervention themes in a wide-scale school-based intervention program designed to reduce cyberbullying in WhatsApp classmate groups. Data were collected from 52 classes in 12 public schools in Israel. Results indicated significantly decreased WhatsApp cyberbullying and a significantly improved classroom climate. However, traditional bullying victimization and other emotional and social factors such as self-esteem and popularity were not measured. The current study is an intervention study that evaluates the effectiveness of the updated version of the intervention program that was described by Aizenkot and Kashy-Rosenbaum (2018) in reducing bullying online and offline and improving student perceived popularity and self-esteem.

The debate concerning co-occurrence between cyberbullying and bullying may be partially answered by evaluating the ability of intervention programs against cyberbullying to reduce traditional bullying as well (Chaux et al., 2016). Some intervention programs aimed to reduce cyberbullying have also shown a decrease in traditional bullying. For example, Garaigordobil and Martínez-Valderrey (2015) found that Cyberprogram 2.0, a program designed to prevent cyberbullying, was able to significantly reduce traditional bullying perpetration and victimization. Similarly, Chaux and colleagues (2016) reported that Media Heroes, a program developed to prevent cyberbullying, led to a reduction in traditional bullying perpetration, although not victimization. Other intervention programs designed to reduce bullying and victimization, online and offline, proved to be effective as well. For instance, Palladino and colleagues (2016) reported about TheNoTrap! program, a school-based intervention that utilizes a peer-led approach to prevent and combat both traditional bullying and cyberbullying. Intervention significantly predicted a decrease in perpetration and victimization of traditional bullying and cyberbullying. Similarly, Ortega-Barón and colleagues (2019) evaluated the effectiveness of the Prev@cib anti-bullying and cyberbullying intervention program. Results showed a significant decrease in bullying and victimization, and cyberbullying and cybervictimization, in the experimental group compared to the control group.

This evidence may suggest that traditional bullying and cyberbullying are related enough for prevention efforts focused on cyberbullying to reduce traditional bullying as well. However, it has been suggested that further research is needed in order to understand the various ways intervention programs against one form of bullying are also effective in reducing the other (Ortega-Barón et al., 2019). Therefore, it is hypothesized that following program implementation, traditional bullying and cyberbullying prevalence will decrease.

\section{The Current Study}

The current study is an intervention study that aims to evaluate the effectiveness of the Safe Surfing anticyberbullying intervention program, based on TPB, for primary, middle, and high school students in Israel, in reducing bullying online and offline and improving student perceived popularity and self-esteem.

This study may capture more fully the experiences of youth (Mitchell \& Jones, 2015), and analyze the ways different variables involved in the process of victimization online and offline are connected and affected by an intervention program against cyberbullying (Cantone et al., 2015). The research may also contribute to the debate regarding the co-occurrence between traditional bullying and cyberbullying and provide important insights for intervention efforts. 
The main hypotheses of this study are that from pre- to post-intervention: (1) cyberbullying prevalence among classmates will decrease; (2) traditional bullying prevalence among classmates will decrease. This decrease will indicate a transference effect of the intervention program contents from virtual class social life to the real one; (3) students' negative perception of their popularity will decrease. This decrease will indicate a distant transference effect of the intervention program contents to the class social life; (4) students' self-esteem will increase. This increase will indicate a distant transference effect of the intervention program contents to the students' emotional state; and (5) in classrooms that there has been a greater decrease of cyberbullying and traditional bullying rates following the intervention program, there will be a greater improvement in students' negative perception of popularity and in students' self-esteem. The research hypotheses will be tested while controlling for student gender and grade-level. Gender and grade-level variables are controlled in the current study due to differences between gender groups and grade-levels in exposure to cyberbullying (Aizenkot \& Kashy-Rosenbaum, 2019) and in prosocial behavior (Van der Graaff et al., 2018).

\section{Method}

\section{Participants}

Data were collected from a total of 1,550 students (53\% males) from 69 classes in 19 public, low to medium socioeconomic level, schools. The students attended $3^{\text {rd }}$ to $11^{\text {th }}$ grades $(68 \%$ in primary school and $32 \%$ in middle and high school; $M=5.52, \mathrm{SD}=1.74$ ). The participants were not asked about their age, but about their grade-level. However, in Israel, children go to first grade at the age of six, so the participants' ages ranged approximately between 8 to 17 years. The average number of children per class was $22.5(S D=5.5)$. There were no significant differences in gender distribution within grade-level groups, $t(67)=0.52, p=.604$. All of the schools participated in the intervention program as part of the Ministry of Education policy. Since this study evaluates the effectiveness of an intervention program that was implemented as part of the Ministry of Education policy, all students who participated in the intervention program participated in the study. The study sample included only classes in which the research questionnaire was administered twice, pre and post-intervention implementation, to at least 10 students in each class. Consequently, $3 \%$ of the classes in which the intervention program was implemented dropped out. In addition, of the classes in which the questionnaire was administered in both measurements, a small percentage of students (3\%) were omitted from the sample due to non-serious or partial filling of the questionnaire.

Since no identifying details were collected from the students, except for school name, grade level, class number, and gender, it was not possible to enable linkage of pre- to post-intervention measurement for each student, only for each class. Therefore, pairing between the measurements pre- and post-intervention was done at the class level using aggregate means for all students within each class.

\section{Measures}

The following questionnaires were used to measure intervention effectiveness: (1) Exposure to cyberbullying among classmates; (2) Exposure to bullying among classmates; (3) Student self-esteem; and (4) Student perceived popularity in class. All questionnaires were administered pre-and post-intervention.

\section{Exposure to Bullying Online and Offline}

The questionnaire is based on previous questionnaires that examined cyberbullying and bullying (Aizenkot, 2017a; Aizenkot \& Kashy-Rosenbaum, 2018; Heiman \& Olenik-Shemesh, 2015; RAMA, 2016; Willard, 2007). Bullying online and offline among students was measured using 12 items divided into two types of bullying: (1) cyberbullying (6 items) and (2) bullying (6 items). For example: "Did it happen this school year that a student from school threatened to hurt another student, at school or after school?" The answer options were: "I was hurt by that once" (1 Point); "I was hurt by that more than once" (2 Points); "It didn't happen to me this year" (0 Points). Two bullying scores were calculated: (1) Score for a cyberbullying victim; (2) Score for a bullying victim. The score options ranged from 0 to 12 , while the higher the score is, the higher the level of victimization. It is important to note that in the questionnaire that was administered post-intervention, the wording of the questions was changed to "Did it 
happen in the past month" instead of "this school year." The pre-intervention questionnaire was administered one month after the beginning of the school year, so the reference of time is similar for both measurements. Cyberbullying was measured with reference to three types of cyberbullying: (1) verbal bullying; (2) doxxing, that is posting personal photos without consent, publishing unsolicited content and posting personal and sensitive information about a student; and, (3) exclusion, that is exclusion from a classmates' group and group rejection. This division was based on a taxonomy first proposed by Willard (2007) and structurally validated by Aizenkot (2017a) and Aizenkot and Kashy-Rosenbaum (2018). Aizenkot and Kashy-Rosenbaum (2018) reported results for a confirmatory factor analysis of the theoretical contraction of a 10-item questionnaire, based on a sample of $N=$ 1407 elementary students. The exploratory factor analysis with varimax rotation results validated the structural division of the questions into distinct dimensions explaining $78 \%$ of the variance between items. Bullying was measured with reference to two types of bullying: (1) verbal bullying; (2) physical bullying (RAMA, 2016). Thus, questions representing the entire dimension were included in the study questionnaire. In the current study, principal axis factor analysis with varimax rotation confirmed the distribution of items into two factors; one included exposure to cyberbullying behaviors ( 6 items, eigenvalue Time $1=2.90$; Time $2=2.89$ ) and the second included exposure to bullying behaviors ( 6 items, eigenvalue Time $1=3.25$; Time $2=2.67$ ), with a total of $48 \%$ explained variance in Time 1 and $49 \%$ in Time 2 (Table 1).

Table 1. Factors Loads of Exposure to Bullying Online and Offline Questionnaire and Internal Reliability Results for Each Factor.

\begin{tabular}{|c|c|c|c|c|}
\hline \multirow{2}{*}{ It happened to me: } & \multicolumn{2}{|c|}{ Time 1} & \multicolumn{2}{|r|}{ Time 2} \\
\hline & Bullying & Cyberbullying & Bullying & Cyberbullying \\
\hline $\begin{array}{l}\text { 8. Did it happen this year that a student from class hit or kicked or } \\
\text { punched another student with the goal of hurting him? }\end{array}$ & .826 & .101 & 831 & .114. \\
\hline $\begin{array}{l}\text { 10. Did it happen this year that a student from class gave a blow to } \\
\text { another child? }\end{array}$ & .777. & .177 & .703 & 254 \\
\hline $\begin{array}{l}\text { 7. Did this year happen that a student from school pushed another } \\
\text { child? }\end{array}$ & .725 & .080 & .762 & .084 \\
\hline $\begin{array}{l}\text { 11. Did this year happen that a student from class threatened to hurt } \\
\text { another student at school or after school? }\end{array}$ & .642 & .309 & .581 & .217 \\
\hline $\begin{array}{l}\text { 9. Did it happen this year that a s a student from class used a stick, } \\
\text { stone, chair, or other object to hurt another student? }\end{array}$ & .527 & .402 & .483 & .449 \\
\hline $\begin{array}{l}\text { 12. Did this year happen that student blackmailed threats from a class } \\
\text { student for money, food, or valuables? }\end{array}$ & .515 & .301 & .509 & .382 \\
\hline $\begin{array}{l}\text { 1. Did it happen this year that another student verbally hurt another } \\
\text { child on a social network? (Threats; curses; insults; ridicule; laughter). } \\
\text { 5. Did it happen this year that another student posted personal }\end{array}$ & .409 & .408 & .255 & .487 \\
\hline $\begin{array}{l}\text { information about another child against his will and for the purpose of } \\
\text { hurting? }\end{array}$ & .073 & .741 & .118 & .739 \\
\hline $\begin{array}{l}\text { 4. Did it happen this year that a student from class called to boycott } \\
\text { another student on a social network, or started another group on a } \\
\text { social network? }\end{array}$ & .235 & .717 & .219 & .709 \\
\hline $\begin{array}{l}\text { 2. Did it happen this year that a student from class posted on another } \\
\text { social network pictures or videos of another student against his will to } \\
\text { annoy him or her? }\end{array}$ & .059. & .690 & .105 & .753 \\
\hline $\begin{array}{l}\text { 6. Did it happen this year that a student from class posted } \\
\text { embarrassing content (pictures; movies; stories) that didn't fit students } \\
\text { age? }\end{array}$ & .138 & .556 & .117 & .643 \\
\hline $\begin{array}{l}\text { 3. Did it happen this year that a student from class started a social } \\
\text { networking group without a particular student who wanted to } \\
\text { participate, or did he remove a student from a group against his will? }\end{array}$ & .244 & .530 & .179 & .624 \\
\hline Explained variance & $24 \%$ & $24 \%$ & $22 \%$ & $27 \%$ \\
\hline Cronbach Alpha & & .70 & & .78 \\
\hline
\end{tabular}

\section{Perceived Popularity in Class}

This questionnaire was taken from the popularity sub-scale (questions no. 1, 3, 11, 37, 39, 41, 47, 51, 57) of the children's self-concept scale (Piers \& Harris, 2002). The questionnaire was originally developed to provide a brief, self-report instrument for the assessment of self-concept in children and adolescents. Self-concept is a relatively stable set of attitudes reflecting both description and evaluation of one's own behavior and attributes (Piers \& 
Harris, 2002). Since its introduction, the Piers-Harris scale (2002) has enjoyed widespread acceptance among clinicians and researchers. The questionnaire was translated into Hebrew by the Israeli Ministry of Education. The original total popularity sub-scale included 12 items, of which 9 were selected for the current study that were found to be appropriate for examining social class perceptions specifically for the classroom, and the formulation of questionnaire items was adapted in the present study specifically to examine students' perceived popularity in the classroom. Items that refer to the student's social competence perception were generally omitted, for example, "I am shy." A 5-point Likert scale from 1 (not true at all) to 5 (very true) was used to rate the questions, for example, "I have many friends." The results of principal axis factor analysis with varimax rotation indicated a structural division of the questionnaire items into two factors, one included a positive perception of students' popularity in class ( 4 items, eigenvalue Time $1=1.71$; Time $2=1.54$ ), and the second included a negative perception of students' popularity ( 5 items, eigenvalue Time $1=3.44$; Time $2=1.54$ ), with a total of $62 \%$ explained variance in Time 1 and 56\% in Time 2 (Table 2). Popularity negative and positive scales were mean scored, so that a higher score indicated more agreement with the content of each scale. Between the two student perception scales of their popularity in the classroom, negative correlations were obtained, with a moderate and significant intensity of -.46 and -.40 for Time 1 and Time 2, respectively. These correlations validate the distinction between the positive and negative scales.

Table 2. Factors Loads of Perceived Popularity Questionnaire and Internal Reliability Results for Each Factor.

\begin{tabular}{lcccc}
\hline \multirow{2}{*}{ Popularity scales } & \multicolumn{2}{c}{ Time 1 } & \multicolumn{2}{c}{ Time 2 } \\
\cline { 2 - 5 } Eigenvalue & Negative & Positive & Negative & Positive \\
\hline My classmates make fun of me & 3.85 & 1.71 & 3.44 & 1.54 \\
\hline People pick on me & 0.80 & -0.06 & 0.77 & -.03 \\
I'm among the last to be chosen for games and sports & 0.78 & -0.01 & 0.76 & .04 \\
I am unpopular & 0.74 & -0.12 & 0.65 & -.21 \\
It is hard for me to make friends & 0.72 & -0.25 & 0.59 & -.27 \\
\hline I have a many friends & 0.61 & -0.38 & 0.59 & -.33 \\
My classmates in school think I have good ideas & -0.21 & 0.85 & -0.19 & .84 \\
During breaks, I'm usually with my classmates & -0.23 & 0.81 & -0.02 & .74 \\
Most of my classmates like me & 0.12 & 0.74 & -0.17 & .74 \\
\hline Explained variance & -0.32 & 0.73 & -0.20 & .75 \\
Cronbach Alpha & $32 \%$ & $30 \%$ & $29 \%$ & $27 \%$ \\
\hline
\end{tabular}

\section{Self-Esteem Scale}

The self-esteem scale (Rosenberg, 1965) assesses normative feelings of self-worth. It contains 10 items such as "On the whole, I am satisfied with myself," rated on a 1 (strongly disagree) to 5 (strongly agree) scale. The questionnaire was translated into Hebrew by Weiss and Yalon-Chamovitz (2007). The Rosenberg Self-Esteem Scale presented high ratings in reliability areas; internal consistency was 0.77 , and the minimum coefficient of reproducibility was at least 0.90 (Hobfoll \& Walfisch, 1984; Rosenberg, 1965). A varied selection of independent studies, each using such samples as - parents, men over 60, high school students, and civil servants - showed alpha coefficients ranging from 0.72 to 0.87 . Internal reliability in the present study was .86 and .81 (Time 1 and Time 2, respectively). Test-retest reliability for the 2.5-month interval was calculated at 0.85, the 7-month interval was calculated at 0.63 (Silber \& Tippett, 1965; Shorkey \& Whiteman, 1978). The results of a principal axis factor analysis indicated the convergence of the questionnaire items into one factor with a total of $79 \%$ and $72 \%$ (Time 1 and Time 2, respectively) explained variance. The self-esteem scale was mean scored, so that a higher score represents more positive self-esteem. 


\section{Procedures}

The intervention program and the follow-up survey were developed for internal use of the Israeli Ministry of Education and monitored by a supervisor from the Ministry of Education. According to the Israeli Ministry of Education regulations, internal data collected as part of the Ministry's regional and national surveys can be used for research purposes (Israeli Ministry of Education, 2015). The first measurement was conducted one week before the beginning of program implementation, and the second measurement one week after program implementation had ended; thus, two and a half months elapsed between the two measurements.

Both pre-and post-intervention questionnaires were answered anonymously and voluntarily. The questionnaires did not include mandatory questions, and penalties were not imposed on students who chose not to complete the questionnaires or not to participate at all. A teacher was present in the classroom while students were filling the questionnaires in order to supervise and keep order. Students' privacy was strictly maintained, and the teacher was instructed not to walk among the students while they completed the survey questionnaires and to respect the privacy of the information provided. Students completed the survey online at school, and the few that were absent from school on the day the questionnaires were administered were given the option to complete them online at home.

The intervention program was implemented by the school's professional staff (school counselors and class teachers). Prior to implementation, the school counselors received training in the intervention program by a regional instructor that supervised the program on behalf of the Ministry of Education. The training included three 2-hour training sessions. School counselors were then requested to conduct the same training in the schools in which they work, as they are used to do in other intervention programs. They conducted the training for the class teachers whose classes would participate in the intervention program. The class teachers were required to implement the program during "Life Skills" lessons. The school counselors submitted progress reports to the regional instructor throughout the class teacher training and program implementation process. The intervention was implemented during school hours, 1 hour per week over a 2-month period.

\section{The Intervention Program}

Schools that participated in the study were involved in a large-scale Safe Surfing intervention program with the aim of reducing cyberbullying in WhatsApp classmate discourse. The design of the intervention program was based on several existing Ministry of Education intervention programs against cyberbullying. Selected themes were taken from these programs and modified according to evidence-based best practices described in the literature (Barkoukis et al., 2016; Wölfer et al., 2014), and from the theory of planned behavior (Ajzen, 1991). The rationale for choosing this theoretical approach derives from studies that successfully explained cyberbullying behavior with the help of this model (Heirman \& Walrave, 2012; Roberto \& Eden, 2010).

The intervention program examined in this study was the second and updated version of a specific intervention program first implemented in 2017 and described by Aizenkot and Kashy-Rosenbaum (2018). The current version of the intervention program consisted of similar topics, but with updated lesson plans and contents.

The current program included eight weekly lesson plans that addressed the following topics: understanding the definition of cyberbullying; expressions and implications of cyberbullying in general and WhatsApp cyberbullying in particular; the role of bystanders, including developing personal and mutual responsibility; acquaintance with state laws prohibiting cyberbullying; developing skills for judging and self-monitoring contents before disseminating them online; and formulating school rules in workshops attended by the entire school population (teachers, students, and parents). Each topic was covered in either one or two lesson plans.

The intervention program was implemented by the school's professional staff (school counselors and homeroom teachers). Prior to implementation, the school counselors received training in the intervention program by a regional instructor who supervised the program on behalf of the Ministry of Education. The training included three 1-hour training sessions. School counselors were then requested to conduct the same training in the schools in which they work, in the same way they implement other intervention programs. They conducted the training for the homeroom teachers whose classes would participate in the intervention program. The homeroom teachers 
were required to implement the program during "Life Skills" lessons. The school counselors submitted progress reports to the regional instructor throughout the homeroom teacher training and program implementation process. The intervention was implemented during school hours, 1 hour per week over a 2-month period.

Intervention themes included the following:

1. Knowledge and competencies. Raise student awareness to relevant legislation and law-breaking involved in cyberbullying; Develop and practice social skills that foster a positive atmosphere and positive communication in WhatsApp classmate groups.

2. Attitudes toward WhatsApp cyberbullying. Change student attitudes towards cyberbullying by providing information about WhatsApp cyberbullying expressions and harmful consequences.

3. Subjective norms. Increase classmate social responsibility in general and of bystanders in particular, develop school rules regarding online communication and digital bullying, define usage norms in WhatsApp classmate groups (including the number of WhatsApp groups in a class, frequency of WhatsApp group turnover and WhatsApp classmate group composition) and encourage parental involvement. The latter is achieved through workshops and lectures for parents conducted by the school psychologist and designed to provide parents with tools for parental involvement and for monitoring their children `s online activity.

4. Perceived behavioral control. Develop strategies for self-behavior monitoring and control, and response strategies in case of cyberbullying.

Various methods were used to effectively convey program content, among them short videos, dilemma-based stories, interactive activities, group-discussion cards, and information provided and discussed (news items, relevant laws, etc.). All lessons began with an informative segment followed by group activities and a discussion. The students' native language is Hebrew, and therefore the survey and the intervention program were both administered in this language (for a full and detailed description of the intervention program see Aizenkot, 2017b).

\section{Data Analysis}

The independent study variables were: (1) measurement time (before and after the intervention program), and (2) exposure to bullying in two spaces (physical and virtual). The independent controlled variable in the study was the school grade-level (primary school and middle and high schools) and gender. The dependent variables in the current study were: (1) exposure to bullying; (2) perceived popularity; and, (3) self-esteem.

Initial descriptive statistics and Shapiro-Wilk tests (Shapiro \& Wilk, 1965) were conducted for variables in order to test for normality of distributions. Results showed a normal data distribution for all pre-post variables scores $(p>.05)$. Accordingly, in order to examine the contribution of the intervention to reduce online and offline bullying in the classroom, three-way $(2 \times 2 \times 2)$ repeated measures MANCOVA was conducted. The first independent variable in the analysis was the time of measurement (2: pre- and post-intervention, within-subject variable), the second independent variable in the analysis was the space of exposure to bullying (2: cyberbullying vs. bullying, withinsubject variable), and the third independent variable was school grade-level (2: primary school vs. middle and high schools, between- subject variable). The dependent variable was exposure to bullying online and offline, controlled by gender (entered as a dummy variable). Then, in order to examine the contribution of the intervention in improving perceived popularity and student self-esteem, two more analyses of two-way $(2 \times 2)$ repeated measures MANCOVAs were conducted. The first independent variable in these analyses was the time of measurement (2: pre- and post-intervention, within-subject variable), and the second independent variable in the analyses was the school grade-level (2: primary vs. middle and high schools, between-subject variable). The dependent variables were student perceived popularity and self-esteem, separately, controlled by gender (entered as a dummy variable). To complete understanding of the effectiveness of the intervention for the degree of improvement in online and offline bullying, student perception of popularity and self-esteem, difference scores were calculated between variable measurements pre- and post-intervention. Difference scores were produced using an option of regression analysis, which calculates the residual scores between the observations (the actual observed value) and the predictions (the predicted value). Pearson correlations between variables residual $Z$ scores to online and offline bullying scores were calculated. After performing this procedure, partial Pearson correlations were calculated between study difference scores, controlled by school grade-level and gender. 


\section{Results}

\section{Intervention Effects on Bullying Online and Offline}

Figure 1. Bullying Online and Offline, Pre- and Post- Intervention $(N=69)$.

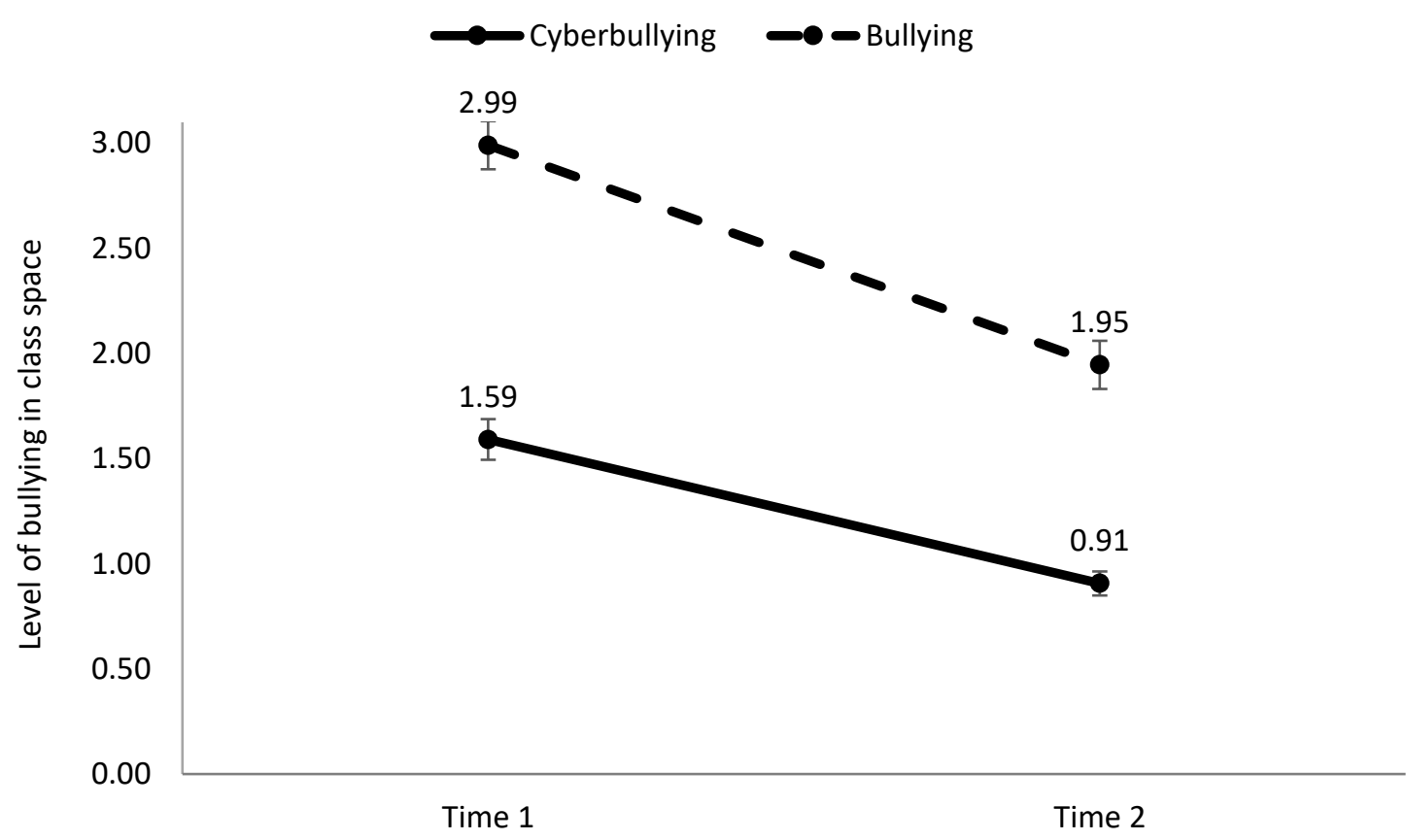

Repeated measures MANCOVA results showed a significant main effect for time of bullying (online and offline) measurement, $F(1,66)=7.36, p=.008, \mu^{2}=.10$. Additionally, a significant interaction was found between time of measurement $X$ type of bullying (online/offline), $F(1,66)=8.26, p=.005, \mu^{2}=.11$, after controlling for school gradelevel and gender. Simple main effect follow-up tests, using the t-test pairs to examine the source of the variance in the significant interaction obtained, showed that there was a significant decrease in both types of bullying: online, $t(68)=8.25, p<.001$, and offline, $t(68)=10.21, p<.001$, although there was a significantly larger decrease in bullying compared to cyberbullying. Furthermore, the rate of bullying was found to be significantly higher than the rate of cyberbullying, pre-intervention, $t(68)=16.11, p<.001$, and post-intervention, $t(68)=10.95, p<.001$. However, the gap between bullying online and offline was reduced significantly from pre- to post-intervention. The results are shown in Figure 1 below.

\section{Intervention Effects on Student-Perceived Popularity and Self-Esteem}

\section{Negative Perception of Popularity}

Repeated measures MANCOVA results showed no significant main effect for time of negative perception of popularity measurement, $F(1,66)=0.18, p=.892, \mu^{2}=0$. However, on the limit of statistical significance, interaction was found between time of measurement and school grade-level, $F(1,66)=3.90, p=.052, \mu^{2}=.05$, after controlling for gender. Simple main effect follow-up tests, using the t-test pairs in each school level separately to examine the source of the variance in the interaction obtained, showed that there was a significant decrease in negative perception of popularity among primary school students, $t(46)=2.87, p=.003$, while no similar decrease was found among middle and high school students, $t(21)=0.33, p=.374$. The results are shown in Figure 2 below. 
Figure 2. Negative Perception of Social Popularity, Pre-and Post- Intervention $(N=69)$.

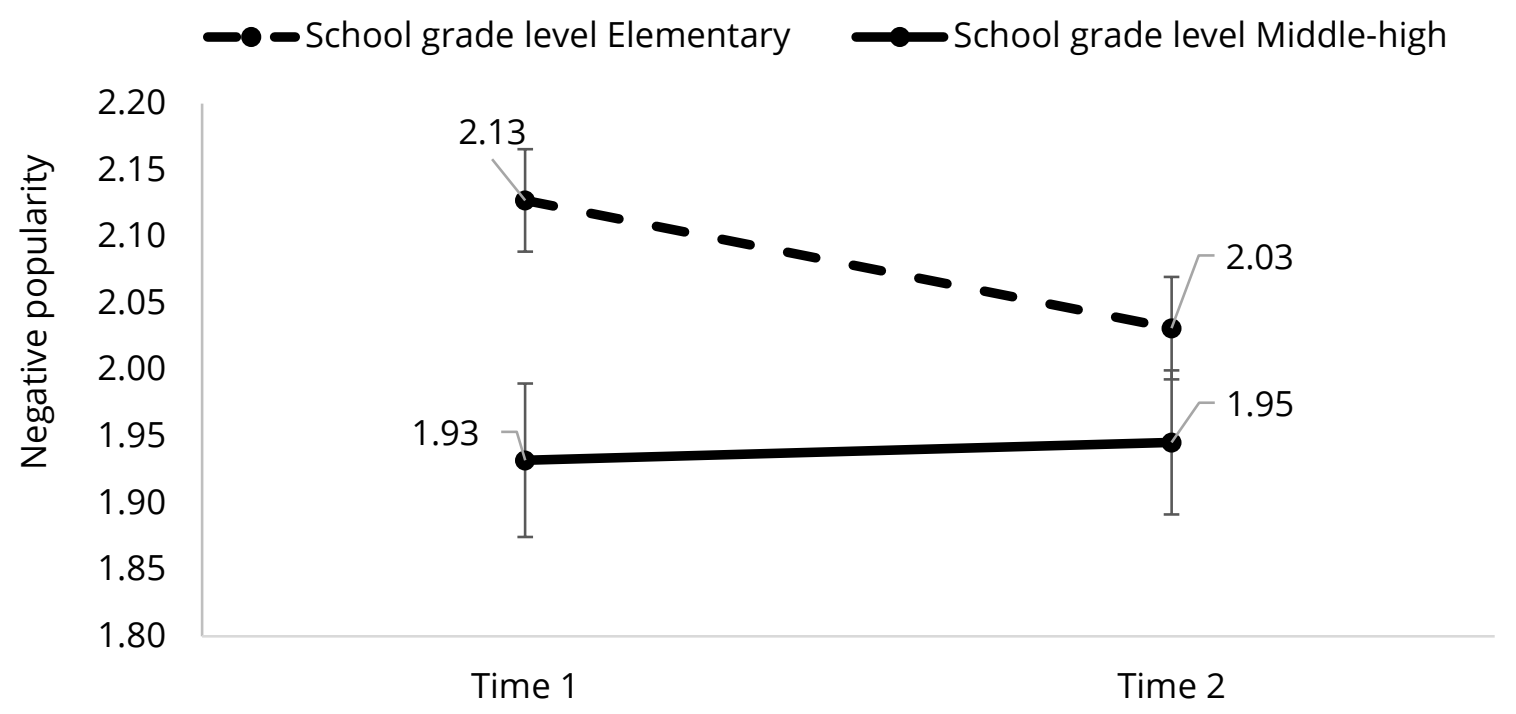

\section{Positive Popularity}

Repeated measures MANCOVA results showed no significant main effect for time of positive perception of popularity measurement, $F(1,66)=0.69, p=.411, \mu^{2}=.01$, and no significant interaction was found between time of measurement and school grade-level, $F(1,66)=2.34, p=.131, \mu^{2}=.03$, after controlling for gender.

\section{Self-Esteem}

Repeated measures MANCOVA results showed no significant main effect for time of self-esteem measurement, $F(1,66)=0.73, p=.397, \mu^{2}=.01$. However, a significant interaction was found between time of measurement and school grade-level, $F(1,66)=10.54, p=.002, \mu^{2}=.14$, after controlling for gender. Simple main effect follow-up tests, using the t-test pairs in each school level separately, showed that there was a significant increase in selfesteem among primary school students from pre- to post-intervention, $t(46)=1.79, p=.041$, while there was a significant decrease in self-esteem among middle and high school students from pre- to post-intervention, $t(21)=$ $2.81, p=.006$. The results are shown in Figure 3 below.

Figure 3. Student Self-Esteem, Pre- and Post- Intervention ( $N=69)$.

— School grade level Elementary $\longrightarrow$ School grade level Middle-high

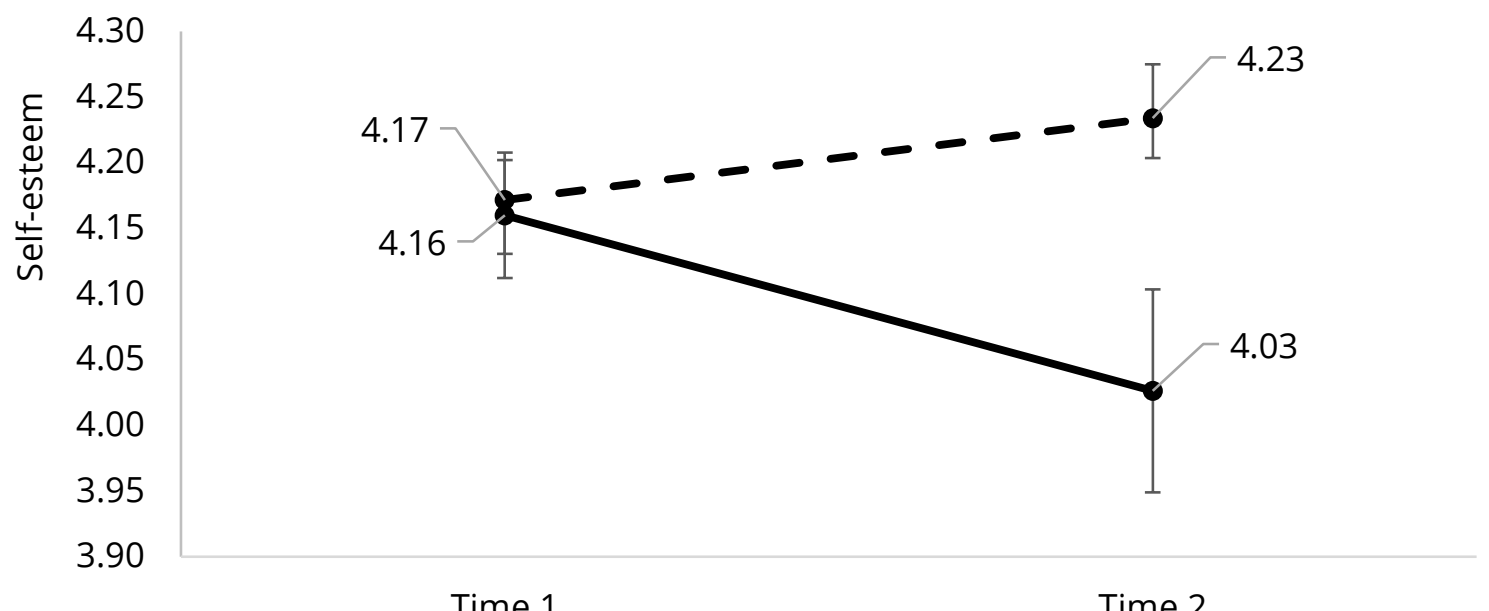

Time 1

Time 2 


\section{Relationships Between the Effects of the Intervention Program}

The correlations obtained between the difference scores indicate that the decrease in cyberbullying and bullying was significantly associated with the decrease in the negative perception of popularity and the increase in selfesteem. These findings support the research hypothesis. Furthermore, it was found that there was a significant negative correlation between the extent of a decrease in negative popularity perception and the increase in positive popularity perception. Subsequently, this increase has a positive and significant strong linear association with the increase in self-esteem. The results are shown in Table 3 below.

Table 3. Pearson Partial Correlations Between Difference Scores, Controlled by School Grade Level and Gender $(N=69)$.

\begin{tabular}{|c|c|c|c|c|}
\hline Difference scores & 1 & 2 & 3 & 4 \\
\hline 1. Cyberbullying & 1 & & & \\
\hline 2. Bullying & $.47 * \star \star$ & 1 & & \\
\hline 3. Negative popularity & $.45 * \star *$ & $.52 * \star \star$ & 1 & \\
\hline 4. Positive popularity & -.19 & .02 & $-.36 * \star$ & 1 \\
\hline 5. Self-esteem & $-.22 * \star$ & $-.21 *$ & $-.42 * \star \star$ & $.70 * \star \star$ \\
\hline
\end{tabular}

Note. ${ }^{* \star} p<.01 ;{ }^{* \star *} p<.001$. One-tail.

\section{Discussion}

The aim of the present study was to examine the effectiveness of a Safe Surfing anti-cyberbullying intervention program in reducing bullying online and offline and improving student-perceived popularity and self-esteem among primary, middle, and high school students. This study is a response to the call for high-quality evaluations of intervention programs against bullying across multiple environments, offline and online, that approach peers victimization with a broad view and capture the full experiences of youth (Ortega-Barón et al., 2019).

The results provide some support that the intervention goals were achieved. Following program implementation, a significant decrease in bullying online and offline was obtained. Furthermore, student negative perception of popularity decreased, and self-esteem increased post-intervention among primary school students. Also, the decrease in bullying online and offline was significantly associated with the decrease in the negative perception of popularity and the increase in self-esteem. Results were significant beyond gender, which indicates that gender did not have a moderating effect on the program. These findings were in line with the study hypotheses. Overall, this study provides some support for the positive role that school-based interventions against cyberbullying in social networks can have, and demonstrates that schools can make a difference in the way their students approach and consume social networks.

The findings may also contribute to the debate about co-occurrence between traditional bullying and cyberbullying by indicating that an anti-cyberbullying intervention program is able to reduce traditional bullying in addition to cyberbullying, similar to several previous studies (Chaux et al., 2016; Garaigordobil \& MartínezValderrey, 2015), and thus supporting the continuity and co-occurrence between bullying online and offline. Another way to interpret these findings is by considering that when cyberbullying between classmates is concerned, the classmates involved are socially related, since they know each other and spend time together, physically during school hours and virtually after school (Aizenkot, 2017a). Furthermore, it has been argued that school-based intervention programs cover a wide range of both interpersonal and intrapersonal factors and therefore foster positive social relationships between classmates, online and offline (Durlak \& DuPre, 2008). It, therefore, seems logical that the impact of such intervention programs should be reflected in both online and offline social environments. It is noteworthy, however, that the reduction in offline bullying post-intervention was bigger than that of cyberbullying. This finding may be explained given that pre-intervention traditional bullying was higher than cyberbullying, and thus the regression toward the mean in traditional bullying was more prominent post-intervention. This gap between traditional bullying and cyberbullying has been observed in previous research that reported that traditional bullying victimization is far more prevalent than cyberbullying victimization (Payne \& Hutzell, 2017). Yet, given the few studies on this topic (Chaux et al., 2016), more research is needed in order to further understand the impact of intervention programs against cyberbullying on bullying online and offline. 
The findings also indicated a decrease in the negative perception of popularity and an increase in self-esteem among primary school students post-intervention. Furthermore, the decrease in bullying online and offline was associated with a decrease in the negative perception of popularity and an increase in self-esteem. These findings mean that intervention programs against cyberbullying can have a significant contribution to students' adjustment and emotional and social functioning, as they improve two important aspects of positive development and adjustment during adolescence, namely perceived popularity and self-esteem (Sullivan, 1953). These findings can be explained given that popularity and self-esteem are predicted by bullying victimization. Previous research has found that victims of traditional bullying and cyberbullying tend to have lower self-esteem (Extremera et al., 2018) and that victims of bullying are lower in perceived popularity compared to non-victims (Cook et al., 2010; de Bruyn et al., 2010). The present study contributes to our knowledge by pointing out the negative relation between cyberbullying victimization and perceived popularity. This relation can be explained given that a substantial number of cyberbullying victims are bullied by peers they know from school (Juvonen \& Gross, 2008; Kowalski \& Limber, 2007; Slonje \& Smith, 2008), and that cyberbullying victims are often the same students who are victims of traditional bullying (Tokunaga, 2010; Twyman et al., 2010). It is, therefore, logical that as bullying online and offline decreases, students' self-esteem and perceived popularity would improve.

The improvement of self-esteem and perceived popularity was only found; however, among primary school students. Middle and high school students showed no change in the negative perception of popularity and a decrease in self-esteem post-intervention. Since bullying online and offline decreased at all school-levels, and the relation between bullying victimization and popularity (Cook et al., 2010) and self-esteem (Extremera et al., 2018) has been established in previous research, it can be assumed that other processes that were not measured in the current study might have influenced middle and high school participants' perceptions of popularity and selfesteem. For instance, the academic load that typically characterizes middle and high schools more than primary school (Telegina \& Belicheva, 2016) has been found to be negatively correlated with self-esteem (Konkabaeva et al., 2013). Since the second measurement was conducted towards the end of the second semester, a period loaded with exams and educational requirements, the increased academic load might have affected students' perceptions of self-esteem. More research is needed, however, in order to further reveal the possible factors that led to a decrease in self-esteem among middle and high school students.

\section{Implications}

These findings have important implications for intervention and policy in the school setting. Understanding the relations between traditional bullying and cyberbullying, and their connection to students' perceived popularity and self-esteem, may encourage school principals and counselors to approach peer victimization with a broader view, and thus capture the full experiences of students. This can constitute the basis for the development and implementation of intervention programs that capture students' social experiences more holistically, and consequently cover a wide range of students' social experiences, online and offline. Such intervention programs may promote students' well-being multi-dimensionally.

In the current study, school counselors received training in the program and trained the class teachers. However, there was no unified manual for training and monitoring program implementation. As noted by Tanrikulu (2018), intervention programs necessitate step by step manuals explaining the systematic implementation procedure. Only by such practical manuals will anti-cyberbullying intervention programs be able to become more widespread and be effectively implemented in the school context. Therefore, it is recommended that practitioners working in schools, and aiming to effectively implement anti-cyberbullying intervention programs such as the program described in the current study, develop unified manuals for teacher training, program implementation and monitoring program implementation.

School policy should also be broadened to include cyberbullying as a virtual form of bullying, and develop regulations and norms prohibiting both forms of peer victimization and encouraging safe and respectful peer communication. For instance, school policy regarding traditional bullying usually provides rules about proper behavior followed by behavioral examples of violation of each rule and the suitable educational responses. The same is advised for cyberbullying. In order for the policy to be implemented and followed through, several steps should be taken. First, school policy should be published among all school population, i.e., students, teachers, and parents. Additionally, lesson plans and workshops designed to assimilate the school policy should be developed 
and implemented, beginning with the educational staff and then among the students. The intervention program described in the current research includes examples of these suggestions, that is, lesson plans designed to develop school policy concerning cyberbullying and to assimilate the school policy that was developed among the school population.

\section{Limitations and Recommendations for Future Research}

Some limitations of the current study should be considered when interpreting the findings. The main weakness of the current study is the lack of a control group due to the fact that the intervention program was implemented in all classes of the schools that participated in the survey, as a policy of the Israeli Ministry of Education. Consequently, an important aspect of the findings' validity is lacking. Nonetheless, research has shown that aggressive behavior tends to escalate over time if no measures are taken against it. In recent research that evaluated the effectiveness of an anti-cyberbullying intervention program, the control group showed increased cyberbullying in the second measurement (Aizenkot \& Kashy-Rosenbaum, 2018). Similarly, Beldean-Galea and colleagues (2012) evaluated the effectiveness of an intervention program aimed to reduce aggressive behavior among $4^{\text {th }}$ to $8^{\text {th }}$-grade students. While results indicated a significant reduction of aggressive behavior in the experiment group, the control group demonstrated the opposite trend (Beldean-Galea et al., 2012). The authors concluded that if schools do not take active measures to eradicate aggressive behavior, it tends to increase. However explicit, these findings do not redundant the need for a control group, and future research should address this deficiency in order to validate the research findings by eliminating alternative explanations.

Furthermore, as part of the Ministry of Education policy, the questionnaires were anonymous and did not include any means of identification apart from grade-level, grade number, and gender. This did not allow for the pairing of questionnaires pre- and post-intervention. This limitation compelled us to measure the improvement at the classroom level (class aggregate means) and not the student level. Consequently, individual changes postintervention may be better investigated in future research.

Another limitation derives from the short time that elapsed between the end of program implementation and the second measurement. The second measurement was conducted one week after the program implementation had ended. Consequently, the study can only assess the short-term effect of the program. It is therefore advised that future research will measure the long-term program effect as well.

The measurement tool developed for the purpose of the survey, based on proposals made by Willard (2007) and Aizenkot (2017a), may contribute to knowledge by presenting two parameters of measurement: type of bullying (online/offline) and role (bully/victim). Nonetheless, the measurement tool did not enable an examination of the data according to the underlying theory of the intervention program. Consequently, the findings could only be interpreted according to the program goals and enabled an evaluation of the program's efficacy. It is therefore advised that in future research, the measurement tool will be adapted to include the components underlying the TPB, i.e., knowledge, competencies, attitudes, norms, and perceived behavioral control.

More broadly, the present multilevel evaluation design enabled us to examine the program's efficacy. However, this conservative method lacks statistical power for more detailed forms of analyses that would allow verifying the theoretically postulated factors by which the program is assumed to unfold its efficacy. In order to evaluate whether the intervention program effectively addresses knowledge, competencies, attitudes, norms and perceived behavioral control, which are assumed to lead to an intended and actual decrease in traditional bullying and cyberbullying, further studies with different statistical approaches are needed for analyzing the operating mechanisms of this program.

Finally, another recommendation for future research derives from the finding concerning the ability of an anticyberbullying intervention program to reduce traditional bullying. It is recommended to examine the opposite direction, that is, the prospect of intervention programs against traditional bullying to reduce cyberbullying as well. 


\section{Conclusion}

The current study demonstrates that a theory-based anti-cyberbullying intervention program is effective in reducing cyberbullying among school-aged students. School seems to be a natural setting where intervention efforts can be practically and effectively performed since, with the commitment of the school principal and the educational staff, cyberbullying intervention programs can be implemented and easily reach the target population.

Moreover, fighting cyberbullying within the school setting through intervention programs can yield wide positive results in reducing not only cyberbullying but also traditional bullying, as well as improve student perceived popularity and self-esteem and thus can make an important contribution to students' positive emotional and social development. The findings of this study may encourage school principals and counselors to implement whole-school interventions that approach peer victimization with a broad view and capture the experiences of youth holistically.

\section{References}

Adler, P. A., Kless, S. J., \& Adler, P. (1992). Socialization to gender roles: Popularity among elementary school boys and girls. Sociology of Education, 65(3), 169-187. http://dx.doi.org/10.2307/2112807

Aizenkot, D. (2017a). חל וץ מחקר :ב ישראל נוער וב ני ילד ים בקרב ב ו וטסאפ ש י ימ ינג [WhatsApp cyberbullying among children and adolescents in Israel: A pilot research]. Educational Counseling, 20, 363-389.

https://www.shaanan.ac.il/wp-content/uploads/2018/01/20-gilayon-male-1.pdf

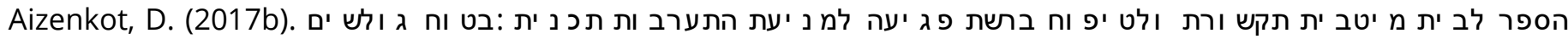

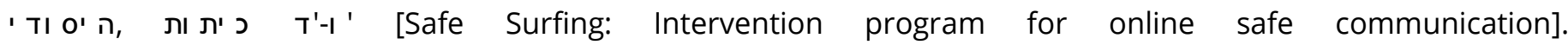
https://drive.google.com/file/d/14pP_hpKK5b6QzaghLYI-V-XrMQ_mLULR/view

Aizenkot, D., \& Kashy-Rosenbaum, G. (2018). Cyberbullying in WhatsApp classmates' groups: Evaluation of a prevention program implemented in Israeli elementary and middle schools. New Media \& Society, 20(12), 47094727. https://doi.org/10.1177/1461444818782702

Aizenkot, D., \& Kashy-Rosenbaum, G. (2019). Cyberbullying victimization in WhatsApp classmate groups among Israeli elementary, middle, and high school students. Journal of Interpersonal Violence. Advance online publication. https://doi.org/10.1177/0886260519842860

Ajzen, I. (1991). The theory of planned behavior. Organizational Behavior and Human Decision Processes, 50(2), 179-211. https://doi.org/10.1016/0749-5978(91)90020-T

Badaly, D., Kelly, B. M., Schwartz, D., \& Dabney-Lieras, K. (2013). Longitudinal associations of electronic aggression and victimization with social standing during adolescence. Journal of Youth and Adolescence, 42(6), 891-904. https://doi.org/10.1007/s10964-012-9787-2

Barkoukis, V., Lazuras, L., Ourda, D., \& Tsorbatzoudis, H. (2016). Tackling psychosocial risk factors for adolescent cyberbullying: Evidence from a school-based intervention. Aggressive Behavior, 42(2), 114-122.

https://doi.org/10.1002/ab.21625

Beldean-Galea, I. E., Ţigan, Ş. I., Stan, C., \& Dobrean, A. (2012). Efficacy study of a primary intervention school violence program. Applied Medical Informatics, 31(3), 47-54.

http://ami.info.umfcluj.ro/index.php/AMI/article/view/388/pdf

Brighi, A., Guarini, A., Melotti, G., Galli, S., \& Genta, M. L. (2012). Predictors of victimisation across direct bullying, indirect bullying and cyberbullying. Emotional and Behavioural Difficulties, 17(3-4), 375-388.

https://doi.org/10.1080/13632752.2012.704684 
Brown, S. L., Birch, D. A., \& Kancherla, V. (2005). Bullying perspectives: Experiences, attitudes, and recommendations of 9- to 13-year-olds attending health education centers in the United States. Journal of School Health, 75(10), 384-392. https://doi.org/10.1111/j.1746-1561.2005.tb06642.x

Cantone, E., Piras, A. P., Vellante, M., Preti. A, Daníelsdóttir, S., D'Aloja, E., Lesinskiene, S., Anermeyer, M. C., Carta, M. G., \& Bhugra, D. (2015). Interventions on bullying and cyberbullying in schools: A systematic review. Clinical Practice and Epidemiology in Mental Health, 11, 58-76. https://doi.org/10.2174/1745017901511010058

Chaux, E., Velásquez, A. M., Schultze-Krumbholz, A., \& Scheithauer, H. (2016). Effects of the cyberbullying prevention program media heroes (Medienhelden) on traditional bullying. Aggressive Behavior, 42(2), 157-165. https://doi.org/10.1002/ab.21637

Closson, L. M., \& Wantanabe, L. (2018). Popularity in the peer group and victimization within friendship cliques during early adolescence. The Journal of Early Adolescence, 38(3), 327-351.

https://doi.org/10.1177/0272431616670753

Cook, C. R., Williams, K. R., Guerra, N. G., Kim, T. E., \& Sadek, S. (2010). Predictors of bullying and victimization in childhood and adolescence: A meta-analytic investigation. School Psychology Quarterly, 25(2), 65-83.

https://doi.org/10.1037/a0020149

Craig, W., Harel-Fisch, Y., Fogel-Grinvald, H., Dostaler, S., Hetland, J., Simons-Morton, B., Molcho, M., de Mato, M. G., Overpeck, M., Due, P., Pickett, W., the HBSC Violence \& Injuries Prevention Focus Group, \& the HBSC Bullying Writing Group (2009). A cross-national profile of bullying and victimization among adolescents in 40 countries. International Journal of Public Health, 54(2), 216-224. https://doi.org/10.1007/s00038-009-5413-9

de Bruyn, E. H., Cillessen, A. H. N., \& Wissink, I. B. (2010). Associations of peer acceptance and perceived popularity with bullying and victimization in early adolescence. Journal of Early Adolescence, 30(4), 543-566. https://doi.org/10.1177/0272431609340517

de Bruyn, E. H., \& van den Boom, D. C. (2005). Interpersonal behavior, peer popularity and self-esteem in early adolescence. Social Development, 14(4), 555-573. https://doi.org/10.1111/j.1467-9507.2005.00317.x

Desjarlais, M., \& Willoughby, T. (2010). A longitudinal study of the relation between adolescent boys and girls' computer use with friends and friendship quality: Support for the social compensation or the rich-get-richer hypothesis? Computers in Human Behavior, 26(5), 896-905. https://doi.org/10.1016/j.chb.2010.02.004

Durlak, J. A., \& DuPre, E. P. (2008). Implementation matters: A review of research on the influence of implementation on program outcomes and the factors affecting implementation. American Journal of Community Psychology, 41(3-4), 327-350. https://doi.org/10.1007/s10464-008-9165-0

Erdur-Baker, Ö. (2010). Cyberbullying and its correlation to traditional bullying, gender and frequent and risky usage of internet-mediated communication tools. New Media \& Society, 12(1), 109-125.

https://doi.org/10.1007/s10464-008-9165-0

Erdur Baker, Ö., \& Tanrıkulu, I., (2009). Cyber bullying in Turkey its correlates and links to depressive symptoms. Journal of eHealth Technology and Application, 7, 16-23.

Extremera, N., Quintana-Orts, C., Mérida-López, S., \& Rey, L. (2018). Cyberbullying victimization, self-esteem and suicidal ideation in adolescence: Does emotional intelligence play a buffering role? Frontiers in Psychology, 9, Article 367. https://doi.org/10.3389/fpsyg.2018.00367

Gaffney, H., Farrington, D. P., Espelage, D. L., \& Ttofi, M. M. (2019). Are cyberbullying intervention and prevention programs effective? A systematic and meta-analytical review. Aggression and Violent Behavior, 45, 134-153.

https://doi.org/10.1016/j.avb.2018.07.002 
Garaigordobil, M., \& Martínez-Valderrey, V. (2015). Effects of Cyberprogram 2.0 on "face-to-face" bullying, cyberbullying, and empathy. Psicothema, 27(1), 45-51. https://doi.org/10.7334/psicothema2014.78

Gradinger, P., Strohmeier, D., Schiller, E. M., Stefanek, E., \& Spiel, C. (2012). Cyber-victimization and popularity in early adolescence: Stability and predictive associations. European Journal of Developmental Psychology, 9(2), 228243. https://doi.org/10.1080/17405629.2011.643171

Hank, P., \& Baltes-Götz, B. (2019). The stability of self-esteem variability: A real-time assessment. Journal of Research in Personality, 79, 143-150. https://doi.org/10.1016/j.jrp.2019.03.004

Heiman, T., \& Olenik-Shemesh, D. (2015). Cyberbullying experience and gender differences among adolescents in different educational settings. Journal of Learning Disabilities, 48(2), 146-155.

https://doi.org/10.1177/0022219413492855

Heirman, W., \& Walrave, M. (2012). Predicting adolescent perpetration in cyberbullying: An application of the theory of planned behavior. Psicothema, 24(4), 614-620.

Hinduja, S., \& Patchin, J. W. (2010). Bullying, cyberbullying, and suicide. Archives of Suicide Research, 14(3), 206221. https://doi.org/10.1080/13811118.2010.494133

Hinduja. S., \& Patchin, J. W. (2008). Cyberbullying: An exploratory analysis of factors related to offending and victimization. Deviant Behavior, 29(2), 129-156. https://doi.org/10.1080/01639620701457816

Hobfoll, S. E., \& Walfisch, S. (1984). Coping with a threat to life: A longitudinal study of self-concept, social support, and psychological distress. American Journal of Community Psychology, 12(1), 87100. https://doi.org/10.1007/BF00896930

Israeli Ministry of Education (2015). הח י נוך במער כת מחקר ית לפע יל ות ה נהל ים [Procedures for research activity in the education system]. http://apps.education.gov.il/mankal/horaa.aspx?siduri=129\#_Toc256000072

Juvonen, J., \& Gross, E. F. (2008). Extending the school grounds?-Bullying experiences in cyberspace. Journal of School Health, 78(9), 496-505. https://doi.org/10.1111/j.1746-1561.2008.00335.x

Konkabaeva, A. E., Kusherbaev, S. A., Kystaubaeva, Z. T., Tykezhanova, G. M., \& Sadykova, A. J. (2013). The influence of study load on the psycho-emotional state of schoolchildren at schools of innovative type. Evropejskij Issledovatel' , 39(1-2), 109-113.

Kowalski, R. M., \& Limber, S. P. (2007). Electronic bullying among middle school students. Journal of Adolescent Health, 41(Suppl. 6), S22-S30. https://doi.org/10.1016/j.jadohealth.2007.08.017

Kowalski, R. M., \& Limber, S. P. (2013). Psychological, physical, and academic correlates of cyberbullying and traditional bullying. Journal of Adolescent Health, 53(Suppl. 1), S13-S20.

https://doi.org/10.1016/j.jadohealth.2012.09.018

Kowalski, R. M., Morgan, C. A., \& Limber, S. P. (2012). Traditional bullying as a potential warning sign of cyberbullying. School Psychology International, 33(5), 505-519. https://doi.org/10.1177/0143034312445244

LaFontana, K. M., \& Cillessen, A. H. N. (2010). Developmental changes in the priority of perceived status in childhood and adolescence. Social Development, 19(1), 130-147. https://doi.org/10.1111/j.1467-

9507.2008.00522.x

Law, D. M., Shapka, J. D., Hymel, S., Olson, B. F., \& Waterhouse, T. (2012). The changing face of bullying: An empirical comparison between traditional and internet bullying and victimization. Computers in Human Behavior, 28(1), 226-232. https://doi.org/10.1016/j.chb.2011.09.004 
Lazuras, L., Barkoukis, V., \& Tsorbatzoudis, H. (2017). Face-to-face bullying and cyberbullying in adolescents: Trans-contextual effects and role overlap. Technology in Society, 48, 97-101.

https://doi.org/10.1016/j.techsoc.2016.12.001

$\mathrm{Li}, \mathrm{Q}$. (2007). Bullying in the new playground: Research into cyberbullying and cyber victimization. Australasian Journal of Educational Technology, 23(4), 435-454. https://doi.org/10.14742/ajet.1245

Litwack, S. D., Aikins, J. W., \& Cillessen, A. H. N. (2012). The distinct roles of sociometric and perceived popularity in friendship: Implications for adolescent depressive affect and self-esteem. Journal of Early Adolescence, 32(2), 226-251. https://doi.org/10.1177/0272431610387142

Lonardo, R. A., Giordano, P. C., Longmore, M. A., \& Manning, W. D. (2009). Parents, friends, and romantic partners: Enmeshment in deviant networks and adolescent delinquency involvement. Journal of Youth and Adolescence, 38(3), 367-383. https://doi.org/10.1007/s10964-008-9333-4

Machimbarrena, J. M., Calvete, E., Fernández-González, L., Álvarez-Bardón, A., Álvarez-Fernández, L., \& GonzálezCabrera, J. (2018). Internet risks: An overview of victimization in cyberbullying, cyber dating abuse, sexting, online grooming and problematic Internet use. International Journal of Environmental Research and Public Health, 15(11), Article 2471. https://doi.org/10.3390/ijerph15112471

Marsh, H. W., \& O'Mara, A. (2008). Reciprocal effects between academic self-concept, self-esteem, achievement, and attainment over seven adolescent years: Unidimensional and multidimensional perspectives of selfconcept. Personality and Social Psychology Bulletin, 34(4), 542-552. https://doi.org/10.1177/0146167207312313

Martínez-Ferrer, B., Moreno, D., \& Musitu, G. (2018). Are adolescents engaged in the problematic use of social networking sites more involved in peer aggression and victimization? Frontiers in Psychology, 9, Article 801. https://doi.org/10.3389/fpsyg.2018.00801

Mayeux, L., Houser, J. J., \& Dyches, K. D. (2011). Social acceptance and popularity: Two distinct forms of peer status. In A. H. N. Cillessen, D. Schwartz, \& L. Mayeux (Eds.). Popularity in the peer system (pp. 79-102). The Guilford Press.

Mitchell, K. J., \& Jones, L. M. (2015). Cyberbullying and bullying must be studied within a broader peer victimization framework. The Journal of Adolescent Health, 56(5), 473-474.

https://doi.org/10.1016/j.jadohealth.2015.02.005

Navarro, R., Yubero, S., \& Larrañaga, E. (2015). Psychosocial risk factors for involvement in bullying behaviors: Empirical comparison between cyberbullying and social bullying victims and bullies. School Mental Health, 7(4), 235-248. https://doi.org/10.1007/s12310-015-9157-9

O'Keeffe, G. S., Clarke-Pearson, K., \& Council on Communications and Media. (2011). On Communications and media. Clinical report-the impact of social media on children, adolescents, and families. Journal of the American Academy of Pediatrics, 127, 800-804. https://doi.org/10.1542/peds.2011-0054

Olweus, D. (1991). Victimization among school children. In R. Baenninger (Ed.), Advances in psychology (Vol. 76, pp. 45-102). Elsevier. https://doi.org/10.1016/S0166-4115(08)61056-0

Olweus, D. (1993). Bullying at school: What we know and what we can do. Blackwell Publishing.

Olweus, D. (1994). Bullying at school: Basic facts and effects of a school based intervention program. Journal of Child Psychology and Psychiatry, 35(7), 1171-1190. https://doi.org/10.1111/j.1469-7610.1994.tb01229.x

Olweus, D. (2013). School bullying: Development and some important challenges. Annual Review of Clinical Psychology, 9, 751-780. https://doi.org/10.1146/annurev-clinpsy-050212-185516 
Ortega-Barón, J., Buelga, S., Ayllón, E., Martínez-Ferrer, B., \& Cava, M.-J. (2019). Effects of intervention program Prev@cib on traditional bullying and cyberbullying. International Journal of Environmental Research and Public Health, 16(4), Article 527. https://doi.org/10.3390/ijerph16040527

Palermiti, A. L., Servidio, R., Bartolo, M. G., \& Costabile, A. (2017). Cyberbullying and self-esteem: An Italian study. Computers in Human Behavior, 69, 136-141. https://doi.org/10.1016/j.chb.2016.12.026

Palladino, B. E., Nocentini, A., \& Menesini, E. (2016). Evidence-based intervention against bullying and cyberbullying: Evaluation of the NoTrap! program in two independent trials. Aggressive Behavior, 42(2), 194-206. https://doi.org/10.1002/ab.21636

Parkhurst, J. T., \& Hopmeyer, A. (1998). Sociometric popularity and peer-perceived popularity: Two distinct dimensions of peer status. The Journal of Early Adolescence, 18(2), 125-144.

https://doi.org/10.1177/0272431698018002001

Patchin, J. W., \& Hinduja, S. (2006). Bullies move beyond the schoolyard: A preliminary look at cyberbullying. Youth Violence and Juvenile Justice, 4(2), 148-169. https://doi.org/10.1177/1541204006286288

Patchin, J. W., \& Hinduja, S. (2010). Cyberbullying and self-esteem. Journal of School Health, 80(12), 614-621. https://doi.org/10.1111/j.1746-1561.2010.00548.x

Patchin, J.W., \& Hinduja, S. (2012). Cyberbullying: An update and synthesis of the research. In J.W. Patchin, \& S. Hinduja (Eds.), Cyberbullying prevention and response: Expert perspectives (pp. 13-35). New York: Routledge.

Payne, A. A., \& Hutzell, K. L. (2017). Old wine, new bottle? Comparing Interpersonal bullying and cyberbullying victimization. Youth \& Society, 49(8), 1149-1178. https://doi.org/10.1177/0044118X15617401

Pellegrini, A. D., Roseth, C. J., Ryzin, M. J. V., \& Solberg, D. W. (2011). Popularity as a form of social dominance: An evolutionary perspective. In A. H. N. Cillessen, D. Schwartz, \& L. Mayeux (Eds.). Popularity in the peer system (pp. 123-139). The Guilford Press.

Perren, S., Dooley, J., Shaw, T., \& Cross, D. (2010). Bullying in school and cyberspace: Associations with depressive symptoms in Swiss and Australian adolescents. Child and Adolescent Psychiatry and Mental Health, 4, Article 28. https://doi.org/10.1186/1753-2000-4-28

Pham, T., \& Adesman, A. (2015). Teen victimization: Prevalence and consequences of traditional and cyberbullying. Current Opinion in Pediatrics, 27(6), 748-756. https://doi.org/10.1097/MOP.0000000000000290

Piers, E.V., \& Harris, D. B. (2002). Piers-Harris Children's Self-Concept Scale: Second Edition. Western Psychological Services.

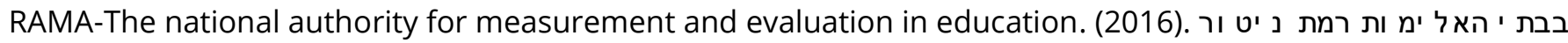

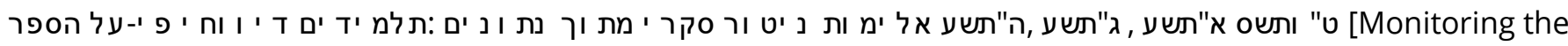
level of violence in schools according to student reports: Data from violence analysis surveys].

https://edu.gov.il/owlHeb/Yesodi/RegulationsAndAdministrations/Safety/Documents/Nitur_Alimut_Report_2015. pdf

Ranney, J. D., \& Troop-Gordon, W. (2020). The role of popularity and digital self-monitoring in adolescents' cyberbehaviors and cybervictimization. Computers in Human Behavior, 102, 293-302.

https://doi.org/10.1016/j.chb.2019.08.023

Roberto, A. J., \& Eden, J. (2010). Cyberbullying: Aggressive communication in a digital age. In T. Avtgis \& A. S. Rancer (Eds.), Arguments, aggression, and conflict: New directions in theory and research (pp. 198-216). Routledge.

Rosenberg, M. (1965). Society and the adolescent self-image. Princeton University Press. 
Runions, K. C. (2013). Toward a conceptual model of motive and self-control in cyber-aggression: Rage, revenge, reward and recreation. Journal of Adolescence, 42(5), 751-771. https://doi.org/10.1007/s10964-013-9936-2

Sandstrom, M. J., \& Cillessen, A. H. N. (2006). Likeable versus popular: Distinct implications for adolescent adjustment. International Journal of Behavioral Development, 30(4), 305-314.

https://doi.org/10.1177/0165025406072789

Shapiro, S. S., \& Wilk, M. B. (1965). An analysis of variance test for normality (complete samples). Biometrika, 52(34), 591-611. https://doi.org/10.1093/biomet/52.3-4.591

Shorkey, C. T., \& Whiteman, V. L. (1978). Correlations between standard English and dialectical Spanish versions of five personality scales. Psychological Reports, 43(3), 910-910. https://doi.org/10.2466/pr0.1978.43.3.910

Silber, E., \& Tippett, J. S. (1965). Self-esteem: Clinical assessment and measurement validation. Psychological Reports, 16(Suppl. 3), 1017-1071. https://doi.org/10.2466/pr0.1965.16.3c.1017

Slonje, R., \& Smith, P. K. (2008). Cyberbullying: Another main type of bullying? Scandinavian Journal of Psychology, 49(2), 147-154. https://doi.org/10.1111/j.1467-9450.2007.00611.x

Slonje, R., Smith, P. K., \& Frisén, A. (2017). Perceived reasons for the negative impact of cyberbullying and traditional bullying. European Journal of Developmental Psychology, 14(3), 295-310.

https://doi.org/10.1080/17405629.2016.1200461

Stice, E., Ragan, J., \& Randall, P. (2004). Prospective relations between social support and depression: Differential direction of effects for parent and peer support? Journal of Abnormal Psychology, 113(1), 155-159.

https://doi.org/10.1037/0021-843X.113.1.155

Sullivan, H. S. (1953). The interpersonal theory of psychiatry. Norton.

Tanrikulu, i. (2018). Cyberbullying prevention and intervention programs in schools: A systematic review. School Psychology International, 39(1), 74-91. https://doi.org/10.1177/0143034317745721

Tanrikulu, i. (2019). How do school children learn cyberbullying perpetration? Journal of Theoretical Educational Science, 12(1), 16-27. https://doi.org/10.30831/akukeg.512556

Telegina, N. V., \& Belicheva, T. V. (2016). The criteria of adaptation of primary school pupils to the academic load of the increased intensity. International Journal of Environmental and Science Education, 11(8), 2059-2067.

http://www.ijese.net/makale/374.html

Tokunaga, R. S. (2010). Following you home from school: A critical review and synthesis of research on cyberbullying victimization. Computers in Human Behavior, 26(3), 277-287.

https://doi.org/10.1016/j.chb.2009.11.014

Trzesniewski, K. H., Donnellan, M. B., Moffitt, T. E., Robins, R. W., Poulton, R., \& Caspi, A. (2006). Low self-esteem during adolescence predicts poor health, criminal behavior, and limited economic prospects during adulthood. Developmental Psychology, 42(2), 381-390. https://doi.org/10.1037/0012-1649.42.2.381

Twyman, K., Saylor, C., Taylor, L. A., \& Comeaux, C. (2010). Comparing children and adolescents engaged in cyberbullying to matched peers. Cyberpsychology, Behavior, and Social Networking, 13(2), 195-199.

https://doi.org/10.1089/cyber.2009.0137

Van der Graaff, J., Carlo, G., Crocetti, E., Koot, H. M., \& Branje, S. (2018). Prosocial behavior in adolescence: Gender differences in development and links with empathy. Journal of Youth and Adolescence, 47(5), 1086-1099. https://doi.org/10.1007/s10964-017-0786-1 
Waasdorp, T. E., \& Bradshaw, C. P. (2015). The co-occurrence between cyberbullying and traditional bullying. Journal of Adolescent Health, 56(5), 483-488. https://doi.org/10.1016/j.jadohealth.2014.12.002

Wang, J., lannotti, R. J., \& Nansel, T. R. (2009). School bullying among adolescents in the United States: Physical, verbal, relational, and cyber. Journal of Adolescent Health, 45(4), 368-375.

https://doi.org/10.1016/j.jadohealth.2009.03.021

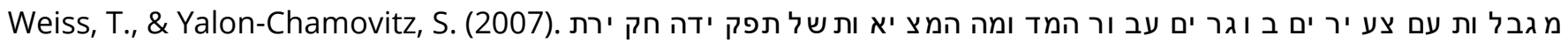
[Investigation of the role of virtual reality for young adults with intellectual and physical impairment]. Haifa University.

Willard, N. E. (2007). Cyberbullying and cyberthreats: Responding to the challenge of online social aggression, threats, and distress. Research Press.

Wölfer, R., Schultze-Krumbholz, A., Zagorscak, P., Jäkel, A., Göbel, K., \& Scheithauer, H. (2014). Prevention 2.0: Targeting cyberbullying at school. Prevention Science, 15(6), 879-887. https://doi.org/10.1007/s11121-013-0438-y

Wong, N., \& McBride, C. (2018). Fun over conscience: Fun-seeking tendencies in cyberbullying perpetration. Computers in Human Behavior, 86, 319-329. https://doi.org/10.1016/j.chb.2018.05.009

Wright, M. F. (2014). Longitudinal investigation of the associations between adolescents' popularity and cyber social behaviors. Journal of School Violence, 13(3), 291-314. https://doi.org/10.1080/15388220.2013.849201

Wright, M. F. (2015). Perceptions of popularity-related behaviors in the cyber context: Relations to cyber social behaviors. Child Development Research, Article 636929. https://doi.org/10.1155/2015/636929

Ybarra, M. L., Boyd, D., Korchmaros, J. D., \& Oppenheim, J. K. (2012). Defining and measuring cyberbullying within the larger context of bullying victimization. Journal of Adolescent Health, 51(1), 53-58.

https://doi.org/10.1016/j.jadohealth.2011.12.031 


\section{Correspondence to:}

Dana Aizenkot

Department of multidisciplinary studies in social science, Ashkelon Academic College

12 Yitzhak Ben-Tzvi ave.

Ashkelon 78211

Israel

Email: dana-aizenkot(at)walla.com

Editorial record: First submission received on October 26, 2019. Revisions received on March 17, 2020, April 15, 2020, July 13, 2020 and July 23, 2020. Accepted for publication on July 26, 2020.

Editor in charge: Michel Walrave

\section{About Authors}

Dana Aizenkot is an associate doctor at Ashkelon Academic College, Israel, department of multidisciplinary studies in social science. Her research interests include cyberbullying in social networks among school-aged children and adolescents, 21 st century skills, and post-traumatic growth following loss and life challenges among children and adolescents.

Gabriela Kashy-Rosenbaum is an associate doctor at Ashkelon Academic College, Israel, Department of Multidisciplinary Studies in Social science. Her research interests include social networks cyberbullying, learning motivation and achievement, well-being, and emotional resilience. 